PUBLIPRENEUR POLIMEDIA: JURNAL ILMIAH
JURUSAN PENERBITAN POLITEKNIK NEGERI MEDIA KREATIF

Vol. 7, No. 2, July 2019

Submitted: 2 Januari 2020

Revised: 16 Januari 2020

Accepted: 29 Januari 2020

\title{
OPTICAL DENSITY OF YELLOW PRINTS AT COATED AND UNCOATED PAPER
}

\author{
Gema Sukmawati Suryadi ${ }^{*}$, Susiani², Mawan Nugraha ${ }^{3}$, Balqis Azhar Ulfah Alifah", \\ Meuthia Suryani ${ }^{5}$. \\ 1-5 Politeknik Negeri Media Kreatif \\ E-mail: gemasukmawati@polimedia.ac.id11, puponsusiani45@gmail.com², \\ manoegra@gmail.com³, balqis.azhar96@gmail.com ${ }^{4}$, icutdirham@yahoo.co.id ${ }^{5}$
}

\begin{abstract}
Optical Density is one of the important parameters used to control print quality. Optical density in print materials is form of interaction of ink with paper. This research is oriented to the investigation of optical density value of Yellow printing ink on coated and uncoated paper. The main purpose of this study is to analyze the effect of printing ink thickness on optimal density value. The optical density value of yellow prints obtained using densitometer measurement, printed using IGT method on coated and uncoated paper. Ink thickness variations are applied $(0.8-9.6 \mu \mathrm{m})$. Density values was found to increase as the ink layer thickness increased to a certain point called the optimal density (2.4 $\mu \mathrm{m}$ ink thickness on coated paper and 4.5 um on uncoated paper). Optical density of yellow printing ink on coated paper is higher uncoated paper, which relates to porosity on paper.
\end{abstract}

Keyword: optical density; offset printing ink; coated paper;

OPTICAL DENSITY TINTA CETAK YELLOW PADA KERTAS SALUT DAN TANPA SALUT

ABSTRAK Optical Density tinta cetak merupakan salah satu parameter penting yang digunakan untuk mengontrol kualitas hasil cetak. Optical density adalah suatu nilai dari kerapatan optik pada material cetak sebagai wujud interaksi tinta dengan bahan cetak khususnya kertas. Penelitian ini berorientasi pada penyelidikan nilai optical density tinta cetak Yellow pada kertas salut dan tanpa salut. Selain itu tujuan utama penelitian ini adalah menganalisis pengaruh ketebalan lapisan tinta terhadap nilai density optimum. Nilai optical density lapisan tinta cetak yellow didapatkan dengan pengukuran menggunakan densitometer pada sampel kertas bersalut dan tanpa salut yang telah dicetak tinta yellow dengan metode IGT. Variasi ketebalan tinta 0,8 - 9,6 $\mu \mathrm{m}$ diterapkan untuk menganalisis pengaruhnya terhadap nilai density optimum. Hasil pengujian menunjukkan bahwa nilai density meningkat seiring dengan peningkatan ketebalan lapisan tinta, hingga pada titik tertentu yang disebut sebagai density optimum (Ketebalan lapisan 2,4 $\mu \mathrm{m}$ pada kertas bersalut dan 4,5 $\mu \mathrm{m}$ pada kertas tanpa salut). Optical density lapisan tinta pada kertas bersalut lebih tinggi daripada kertas tanpa salut. Hal ini berkaitan dengan porositas pada kertas, karena penyerapan varnish pada lapisan tinta.

Kata Kunci: density; tinta cetak offset; kertas bersalut;

\section{PENDAHULUAN}

Optical density atau biasa disebut density tinta adalah suatu nilai dari kerapatan optik pada material cetak sebagai wujud interaksi tinta dengan bahan cetak khususnya kertas. Dalam Fisika Optik, density dari sebuah materi optik adalah nilai pembanding dalam rumusan logaritma (Nuryaman, 2017), dapat didefinisikan :

$D=\log \frac{1}{\beta}=\log \frac{I_{0}}{I}(1)$ 
Faktor reflektansi $\beta$ adalah rasio intensitas cahaya I yang dikirimkan oleh lapisan tinta yang berkaitan dengan intensitas cahaya $\mathrm{I}_{0}$ yang dikirimkan oleh kertas kosong (tanpa lapisan tinta). Faktor refleksi $\beta$ berkurang seiring meningkatnya ketebalan film (Kipphan, 2001).

Dalam proses cetak offset pengukuran nilai density melalui beberapa rangkaian proses terlebih dahulu yaitu proses terjadinya pengalihan tinta cetak melalui roll, plate dan blanket sampai pada kertas cetak. Rangkaian proses dan beberapa material yang terlibat dalam proses cetak tersebut memberikan kontribusi masing-masing dalam perwujudan nilai optical density tinta (Nuryaman, 2017).

Density tinta merupakan salah satu parameter penting yang digunakan untuk mengontrol kualitas hasil cetak. Data density warna diperlukan pada saat proses proofing hasil cetak dan quality control hasil cetak. Nilai density pada hasil proofing digunakan sebagai acuan pengaturan parameter mesin cetak, sehingga hasil cetak akhir pada mesin cetak offset sesuai dengan hasil proofing (Susiani, 2017).

Nilai density tinta dipengaruhi oleh beberapa faktor, diantaranya persentase pigmen dalam tinta cetak. Semakin tinggi jumlah pigmen dalam formulasi tinta, maka density akan semakin meningkat. Namun persentase pigment memiliki batas maksimum sebagaimana perbandingannya dengan komponen lain pada tinta, seperti varnish dan resin. Jika komposisi pigmen terlalu tinggi, hal tersebut berpengaruh terhadap sifat alir tinta yang menyebabkan distribusi tinta melalui roll, plate dan blanket menjadi tidak sempurna.

Faktor lain yang berpengaruh terhadap nilai density adalah proses transfer tinta. Mulai dari bak tinta lalu melewati roll distribusi, kemudian mengalami emulsifikasi dengan air pembasah pada saat tinta tersebut mulai menempel pada plate cetak, yang kemudian bagian image area yang telah dilapisi tinta akan dialihkan terlebih dahulu melalui blanket sebelum akhirnya ditransfer terhadap kertas, rangkaian proses ini terwujud dalam lapisan ketebalan tinta (Ink Film Thickness, IFT). Begitupun halnya dengan jenis kertas, antara kertas yang berpengaruh terhadap nilai density.

Penelitian ini berorientasi pada penyelidikan nilai optical density tinta cetak Yellow pada kertas salut (coated paper) dan tanpa salut (uncoated paper). Selain itu tujuan utama penelitian ini adalah menganalisis pengaruh ketebalan tinta terhadap nilai density optimum, pada kondisi kecepatan dan tekanan cetak yang konstan.

\section{METODE PENELITIAN}

Bahan yang digunakan dalam penelitian ini diantaranya tinta cetak offset yellow (Cemani Toka, jenis Emblem, Indonesia) dan kertas art paper sebagai kertas bersalut dan HVS sebagai kertas tanpa salut. Dilakukan pengujian untuk mengetahui spesifikasi teknis kertas diantaranya gramatur, bulk, kekasaran permukaan, daya serap air, penetrasi minyak, kadar abu, kadar air, brightness, dan opasitas.

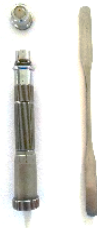

(a)

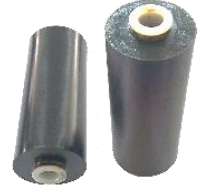

(b)

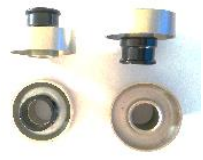

(c) 


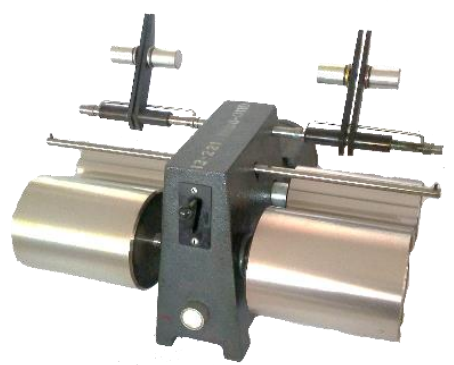

(d)

Gambar 3. (a) IGT ink pipette; (b) roller; (c) printing disc; (d) IGT inking unit AE

Nilai optical density lapisan tinta cetak yellow pada kertas bersalut dan tanpa salut didapatkan dengan pengukuran menggunakan densitometer (X-Rite, seri 500, Canada). Pengukuran dilakukan pada lima titik potongan kertas $(2.5 \times 27 \mathrm{~cm})$ yang telah dicetak tinta yellow menggunakan IGT Inking Unit AE (Belanda) dan IGT A13 (Belanda), dengan tekanan konstan $40 \mathrm{kgf}$, dan variasi ketebalan tinta.

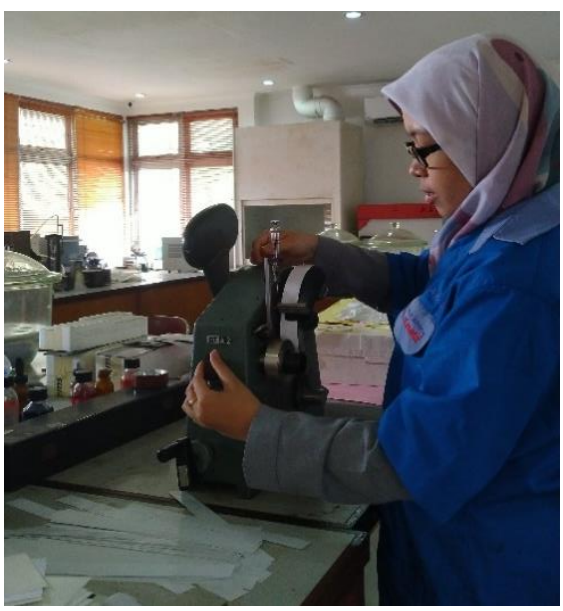

Gambar 4. IGT A1-3 untuk mencetak tinta pada kertas sampel

\section{HASIL DAN PEMBAHASAN}

Pengujian kertas sampel bersalut (art paper) dan tanpa salut (HVS) telah dilakukan, dan disajikan dalam Tabel 1.

Tabel 1. Spesifikasi kertas uji cetak

\begin{tabular}{|c|c|c|c|}
\hline \multirow{2}{*}{ No } & \multirow{2}{*}{ Karakteristik } & \multicolumn{2}{|c|}{ Nilai } \\
\hline & & HVS* & Art Paper \\
\hline 1 & $\begin{array}{l}\text { Gramatur } \\
\left(\mathrm{g} / \mathrm{m}^{2}\right)\end{array}$ & $80,05 \pm 0,33$ & $\begin{array}{c}83,83 \pm \\
0,73 \\
\end{array}$ \\
\hline 2 & Bulk $\left(\mathrm{cm}^{3} / \mathrm{g}\right)$ & 1,28 & 0,91 \\
\hline 3 & $\begin{array}{l}\text { Kekasaran } \\
\left(\mathrm{cm}^{3} / \mathrm{mm}^{2}\right)\end{array}$ & $6,60 \pm 0,33$ & $1,37 \pm 0,05$ \\
\hline 4 & $\begin{array}{l}\text { Daya Serap } \\
\text { Air }\left(\mathrm{g} / \mathrm{m}^{2}\right)\end{array}$ & $26,48 \pm 1,06$ & $\begin{array}{c}20,38 \pm \\
1,05\end{array}$ \\
\hline 5 & $\begin{array}{l}\text { Penetrasi } \\
\text { Minyak } \\
\left(\mathrm{mm}^{-1}\right)\end{array}$ & $27,47 \pm 1,22$ & $8,26 \pm 0,44$ \\
\hline 6 & $\begin{array}{l}\text { Kadar Abu } \\
(\%)\end{array}$ & 11,32 & 23,29 \\
\hline 7 & Kadar Air (\%) & 4,10 & 3,76 \\
\hline 8 & $\begin{array}{l}\text { Brightness } \\
(\%)\end{array}$ & $83,38 \pm 0,4$ & $\begin{array}{c}83,83 \pm \\
0,87 \\
\end{array}$ \\
\hline 9 & Opasitas (\%) & $106,68 \pm 1,2$ & $108,1 \pm 0,2$ \\
\hline
\end{tabular}

* (Susiani, 2016)

Variasi ketebalan lapisan tinta berdasarkan volume tinta yang diaplikasikan pada inking unit, yaitu $0,8 \mu \mathrm{m}-9,6 \mu \mathrm{m}$.

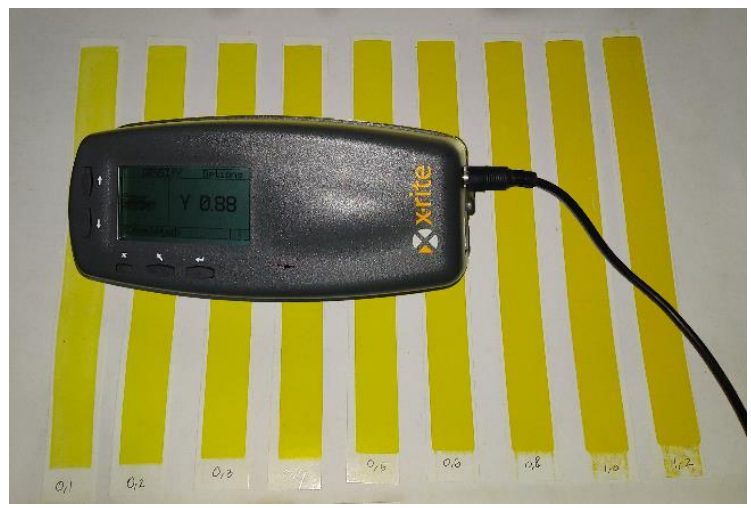

Gambar 5. Pengukuran optical density pada cetakan tinta yellow

Adapun hasil pengukuran optical density terhadap cetakan tinta yellow disajikan pada Tabel 2 untuk kertas HVS dan Tabel 3 untuk kertas Art Paper.

Hasil pengujian menunjukkan bahwa secara keseluruhan nilai density lapisan tinta pada hasil cetak kertas art paper (bersalut) 
lebih tinggi daripada kertas HVS (tanpa salut). Hal ini berkaitan dengan porositas pada kertas. Kertas HVS menyerap lebih banyak varnish pada lapisan tinta, sehingga kerapatan optik pada permukaan HVS lebih rendah dibandingkan dengan art paper. Penyerapan tinta yang dipengaruhi oleh sifat keporian kertas selaras dengan Kipphan (2014), Yang (2015), Leach et al. (2007). Hal ini didukung oleh hasil pengujian spesifikasi kertas yang menunjukkan bahwa nilai faktor bulk $\left(\mathrm{cm}^{3} / \mathrm{g}\right)$ kertas HVS lebih tinggi dari art paper, sehingga kertas HVS memiliki kepadatan massa volumetrik yang lebih rendah karena memiliki lebih banyak poripori pada kermukaan kertas. Data pendukung lain ditunjukkan oleh nilai Penetrasi minyak $\left(\mathrm{mm}^{-1}\right)$ pada kertas HVS jauh lebih tinggi daripada kertas art paper, yang artinya sangat memungkinkan untuk varnish menyerap lebih banyak dibandingkan dengan kertas art paper.

Tabel 2. Nilai Optical Density pada kertas HVS (Susiani, 2017)

\begin{tabular}{|c|c|c|c|}
\hline Volume & \multirow{2}{*}{$\begin{array}{c}\text { Ketebalan } \\
\text { Tinta }\end{array}$} & \multirow{2}{*}{$\begin{array}{c}\text { Tinta } \\
(\mathbf{m L})\end{array}$} & \multicolumn{2}{|c|}{ Optical Density } \\
\cline { 3 - 4 } & $\mathbf{\mu m})$ & HVS-1 & HVS-2 \\
\hline 0,1 & 0,8 & 0,064 & 0,053 \\
\hline 0,2 & 1,6 & 0,287 & 0,287 \\
\hline 0,3 & 2,4 & 0,457 & 0,502 \\
\hline 0,4 & 3,2 & 0,703 & 0,702 \\
\hline 0,5 & 4 & 0,93 & 0,970 \\
\hline 0,6 & 4,8 & 1,092 & 1,157 \\
\hline 0,8 & 6,4 & 1,284 & 1,277 \\
\hline 1 & 8 & 1,349 & 1,360 \\
\hline 1,2 & 9,6 & 1,405 & 1,403 \\
\hline
\end{tabular}

Tabel 3. Nilai Density pada Kertas Art Paper

\begin{tabular}{|c|c|c|c|}
\hline \multirow{2}{*}{$\begin{array}{c}\text { Volume } \\
\text { Tinta } \\
\text { (mL) }\end{array}$} & \multirow{2}{*}{$\begin{array}{c}\text { Ketebalan } \\
\text { Tinta } \\
(\mu \mathrm{m})\end{array}$} & \multicolumn{2}{|c|}{ Optical Density } \\
\hline & & & \\
\hline
\end{tabular}

\begin{tabular}{|c|c|c|c|}
\cline { 2 - 4 } 0,1 & 0,8 & 0,73 & 0,7 \\
\hline 0,2 & 1,6 & 0,952 & 1,094 \\
\hline 0,3 & 2,4 & 1,166 & 1,206 \\
\hline 0,4 & 3,2 & 1,278 & 1,252 \\
\hline 0,5 & 4 & 1,318 & 1,33 \\
\hline 0,6 & 4,8 & 1,366 & 1,386 \\
\hline 0,8 & 6,4 & 1,54 & 1,518 \\
\hline 1 & 8 & 1,604 & 1,602 \\
\hline 1,2 & 9,6 & 1,658 & 1,666 \\
\hline
\end{tabular}

Analisis interaksi tinta dengan kertas dapat dilakukan lebih lanjut dengan metode contact angle. Gerakan dari tetesan tinta pada permukaan kertas bergantung pada energi antarmuka solid-gas (kertas-udara), solid-liquid (kertas-tinta), dan liquid-gas (tinta-udara), yang biasa disebut sebagai tegangan permukaan (Yang, 2015; Suryadi et al., 2017).

Gambar 6. Memperlihatkan pengaruh ketebalan tinta terhadap nilai rata-rata optical density pada kertas HVS dan art paper. Nilai density optimum lapisan tinta yellow pada kertas HVS didapatkan sebesar 1,08

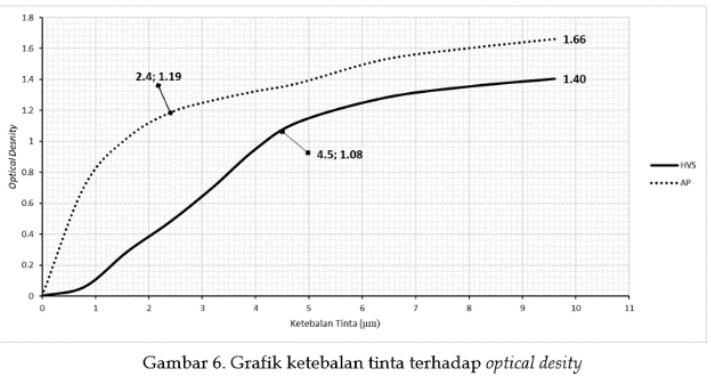

pada ketebalan tinta $4,5 \mu \mathrm{m})$. Hal ini menunjukkan bahwa tidak perlu penambahan ketebalan tinta lagi untuk menambah nilai density warna, berkaitan dengan proses cetak offset untuk efisiensi bahan (tinta) selama produksi. Adapun nilai density optimum lapisan tinta pada kertas art paper adalah 1,19 pada ketebalan tinta 2,4 $\mu \mathrm{m}$. Untuk mencapai density maksimum, lapisan tinta yellow pada kertas art paper lebih tipis dibandingkan pada kertas HVS. Artinya, proses cetak pada 
kertas art paper hanya membutuhkan tinta yang lebih sedikit untuk mendapatkan warna yang optimal.

Selain itu, nilai density maksimum lapisan tinta pada kertas art paper yaitu 1,66, lebih tinggi dari kertas HVS 1,40. Nilai tersebut dapat dicapai pada cetakan dengan ketebalan tinta lebih dari $9 \mu \mathrm{m}$

\section{SIMPULAN}

Ketebalan lapisan tinta cetak berpengaruh pada nilai optical density. Nilai density meningkat seiring dengan peningkatan ketebalan lapisan tinta, hingga pada titik tertentu yang disebut sebagai density optimum. Ketebalan lapisan tinta pada kertas Art paper mencapai 2,4 $\mu \mathrm{m}$ dan pada kertas HVS mencapai $4,5 \mu \mathrm{m}$, berada pada titik optimum, sehingga lebih dari itu peningkatan nilai density terhadap penambahan ketebalan tinta cenderung konstan.

Optical density lapisan tinta pada kertas bersalut lebih tinggi daripada kertas tanpa salut. Hal ini berkaitan dengan porositas pada kertas. Kertas tanpa salut menyerap lebih banyak varnish pada lapisan tinta, sehingga kerapatan optik pada permukaan lebih rendah dibandingkan dengan kertas bersalut

\section{DAFTAR PUSTAKA}

Kipphan, H. (Ed.). (2001). Handbook of Print Media: Technologies and Production Methods. Heidelberg (DE): Springer.

Leach, R.H \& Pierce, R.J. 2007. The Printing Ink Manual. Fifth Edition. Dordrecth (NED): Springer

Muchtar, E., Tapianto, T., Suryani, M., Muryeti, (1998). Pedoman Pengujian Kertas dan Tinta. Jakarta: DEPDIKBUD Pusat Grafika Indonesia

Nuryaman, A. (2017). Berapa nilai Density
Optimum Tinta (CMYK) Cetak Offset. Indonesia Print Media: Graphic Company Information $\mathcal{E}$ Communication Media, 78. Retrieved from

https://www.indonesiaprintmedia. com/cetak-mencetak/605-berapanilai-density-optimum-tinta-cmykcetak-offset-.html

Puceković, N. (2014). Development of BioBased Materials In Printing (Master Thesis). University of Zagreb, Faculty of Graphic Arts.

Robert, T. (2015). Green ink in all colorsPrinting ink from renewable resources. Progress in Organic Coatings. 78, 287-292.

Susiani (2016). Analisis Daya Serap Air pada Tiga Jenis Kertas Cetak: Kertas Koran, Kertas HVS, dan Art Paper. Jakarta: Politeknik Negeri Media Kreatif

Susiani (2017). Pengaruh Ketebalan Lapisan Tinta Terhadap Nilai Density Tinta cetak Offset Pada Kertas HVS. Jakarta: Politeknik Negeri Media Kreatif

Yang, L. (2015). Physical Evaluation of the Quality of Color Halftone. Handbook of Digital Imaging. US: John Wiley \& Sons, Ltd. 